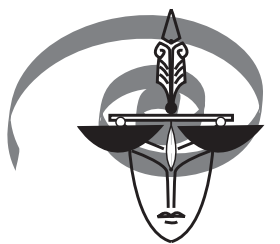

\title{
EUROPEAN
}

Volume $8 \cdot 2014 \cdot$ Number 3 (29)

DOI: 10.2478/ep-2014-0009

Jerzy Konieczny

Opole University, Faculty of Law and Administration

Opole

Poland

\section{Polygraph examination in analysis of evidence}

Key words: polygraph examination as evidence, polygraph examination results, polygraph in criminal case

I assume that a polygraph examination may be part of mass of evidence in a specific case, and I also assume that the result of a polygraph examination belongs to forensic evidence, and within it has its place in expert evidence. Therefore, as item of evidence, it can be subjected to an analysis covering the assessment of its credibility, reliability, weigh, probative force, etc., and can also be analysed as evidential argument. Such an argument may be evaluated from two points of view: "internal" developed by its creator (in this case: by the expert), and "external" whose author is the analyst, or, more generally speaking, the addressee of the argument. The "internal" analysis is presented in (Ibek 2011). This article, in turn, aims at presenting the characteristic features of a polygraph examination result as argument in analysis of evidence.

"jerkonieczny@wp.pl 
Let me begin from applying the concept of a substance-blind approach to evidence. It means that "we can make general statements about the relevance, credibility, authenticity, and probative force without reference to any particular kind of data" (Twining 2006: 441). Therefore, the content of these statements is the particular "hallmark" of a specific method that is sometimes defined as its diagnostic value. One of the first works on the subject was an article whose authors (Widacki, Horvath 1978) proved that the precision of a polygraph examination is not inferior, as it rather exceeds the accuracy of other, generally applied techniques of forensic identification (handwriting, fingerprint, and eyewitness identification). The same comment was maintained also much later: "polygraphy, when considered in relation to other commonly used forensic techniques, yields comparable and, in some cases, superior accuracy" (Horvath 2000: 1108). In turn, in reference to the numerical method applied in the interpretation of the CQT tests, it was established that "numerical scoring by adequately trained and experienced interpreters produced extremely high reliability that compares favorably with any psychological test interpreted by humans" (Raskin, Honts 2002: 21). In a substanceblind approach, these comments define the high position of polygraph examinations.

It must, however, be considered in what way the above brings specific consequences for the analysis of evidence. A general representation of an evidence argument in the case we find interesting is as follows:

Evidence "in hand": the expert claims that $A$, then

Conclusion: $A$.

Oversimplifying, yet without harm to the essence of the case, the conclusions of a polygraph examination may have the following form: the subject of polygraph examination belongs to DI or NDI group. Therefore, the argument used as evidence above has the following form:

Evidence: Expert claims that the subject of a polygraph examination belongs to group DI (or NDI),

Conclusion: the subject of a polygraph examination belongs to group DI (or NDI).

In this argument, like in nearly every argument used as evidence, the conclusion does not result from the premise, therefore, it is a logically invalid argument. The element that connects the premise and the conclusion in this case is a generalisation that justifies conducting an inference towards a specified 
goal. In the case of expert evidence, generalisation usually assumes the form of "if an expert asserts that $A$, then $A$ ". Thus, the argument is hereby developed into the following form:

Evidence: Expert claims that the subject of a polygraph examination belongs to DI (or NDI) group,

Generalisation: if the expert asserts that subject of a polygraph examination belongs to DI (or NDI) group, then the subject of a polygraph examination belongs to DI (or NDI) group,

Conclusion: the subject of the polygraph examination belongs to DI (or NDI) group.

The generalisation made above ("if expert asserts that $A$, then $A$ ") seems difficult if not impossible to question in the case of expert evidence.

In our case, however, the main problem is not the accuracy of the generalisation applied, the more so as the direction of the train of thought defines is natural (Are experts not used to present the observations to be accounted for in evidential reasoning?), but justification that the application of the generalisation is correct in a specific case. In other words, what needs answering is the question why we can/should assume in a given case that if the expert asserts that $A$, then $A$ ? The question is the more significant as the subject performing the analysis, that is the analyst as well as the lawyer making the decision in the litigation, is not an expert in the field of the given expertise.

The problem of justifying generalisations may also be interpreted as a tendency to avoid risk related to forensic evidence. Three types of such risks are identified: (1) defectiveness of the theory that the expert used as the grounds for the statements, (2) a competently conducted examination, (3) defects in the interpretation of the results acquired, and even - in extreme cases making them up (Spencer 2000: 549-550).

The essence of justification of the generalisation, known also as generalisation support is to indicate relevant ancillary evidence. Forensic evidence is worthless without ancillary evidence (Schum 2001: 112). As far as has already been mentioned, a generalisation justifies the specific cause of reasoning and ancillary evidence allows assessment of the scope and probability of the conclusion. There may be various approaches to indicating ancillary evidence. One of them - presented in (Walton 2008: 42) - means obtaining an answer to the following questions: "How credible is $E$ as an expert source? (...) Is $E$ an expert in the field that $A$ is in? (...) What $\operatorname{did} E$ asserts that implies $A$ ? (...) 
Is $E$ personally reliable as an source? (...) Is $A$ consistent with other experts asserts? (...) Is $A$ 's assertion based on evidence?". Positive answers to these questions provide a justification for the generalisation applied, and in this case the argument - developed even further - would assume the following form (let's assume that $A=$ subject of polygraph examination belongs to group DI (or NDI)

Evidence: the expert asserts that $A$, Generalisation: if the expert asserts that $A$, then $A$, Ancillary evidence: $E$ is credible as an expert source, $E$ is personally reliable as a source, $E$ confirmed the presence of facts $f_{1}, f_{2}, f_{3}, \ldots, f_{n}$ that imply $A, A$ is coherent with assertions of other experts, facts $f_{1}, f_{2}, f_{3}, \ldots, f_{n}$ actually occurred,

Conclusion: then $A$.

In this case, the conclusion from evidence is certainly well justified. It must, however, be noted that from the analytical point of view, the questions proposed by $\mathrm{D}$. Walton may be difficult to apply. The reasons for such difficulties may be following: first, it is not easy what criteria to use for the estimation of the expert's credibility and personal reliability. Secondly, the assertion of facts $f_{1}, f_{2}, f_{3}, \ldots, f_{n}$ occurring belongs to the scope of expert knowledge, and therefore, in principle, is not available to the analyst. It is basically an interpretation of the charts acquired from the tests performed as part of polygraph examination. Thirdly, it is not known whether the answer to the question "is $A$ consistent with other experts assertions?" concerns the polygraph examination in question, or also other expert opinions, or whether it can be interpreted extensively and then the coherence of $A$ should be analysed with other items of evidence, for example, with witness testimonies. That is why it seems better to seek ancillary evidence in a different manner.

There are three starting points for the assessment of the "external" correctness of a polygraph examination. The first concerns the technique applied, the second - qualifications of the expert conducting the examination, and the third - the laboratory in which the examination was conducted. Let's notice that the first question also eliminates J. R. Spencer's emphasised doubts (mentioned above) concerning the correctness of the theory providing the foundation of the examination, the second doubt embraces the expert's competencies, and the third is related to the doubts around the quality of the examination. 
Therefore, the first ancillary evidence is the confirmation that one of the validated techniques of polygraph examination was used in the given examination. A list of such techniques can be found in literature (Krapohl 2006, Meta-analytic survey 2011). It needs emphasising that, according to APA standards (broadly accepted also beyond the US), it is possible to use a polygraph examination in the body of evidential arguments only if the accuracy of the technique applied reaches at least $90 \%$, with the exclusion of inconclusive results (more on the subject: Gołaszewski 2013).

Another part of ancillary evidence is corroboration of the expert's qualifications. Usually they are authenticated by a valid certificate of the examiner. "The goal of certification for personnel is to provide a formal and objective guarantee that a candidate has a minimal level of knowledge, skills, and abilities (...) in a given discipline." (Stauffer, Schiffer 2009: 2548). Certificates are issued by international institutions, yet certification is frequently provided within the institution that employs the experts.

The third element of ancillary evidence is related to the quality of expertise. An appropriate level of quality can be obtained in various ways (Gołaszewski 2013: 72-74), yet it is best expressed by the accreditation of the laboratory in which the examination was conducted. Accreditation is the "formal recognition that a testing laboratory is competent to carry out specific tests or specific types of tests" (Schiffer, Stauffer 2009: 11).

Should one agree that the three elements listed above are valid for the justification of the generalisation discussed above, the argument we consider has the following form:

Evidence: Expert $E$ asserts that $A$,

Generalisation: if the expert asserts that $A$, then $A$,

Ancillary evidence: a validated technique was used for conducting the examination, $E$ has a valid certificate validating his or her competencies, and the laboratory where the examination was conducted is accredited, with the accreditation approving the policy ensuring appropriate quality of the performed expert analyses,

Conclusion: then $A$.

Also in this case, one can assume that the conclusion $A$ is very well justified, yet one can also ask whether the presented list of ancillary evidence is sufficient, i.e. whether it can be treated as satisfactory in each case. The answer is unquestionably negative, because the list of ancillary evidence can - at 
least theoretically - be expanded at infinitum. The limits are defined by the context of the analysis (e.g. when certain doubts would not be eliminated by the information provided above) and common sense. A small aside: most probably the list of ancillary evidence quoted above could be aligned with D. Walton's concept, yet there is no need to consider the subject in this place.

Another circumstance, very important for the analysis, results from the remark that a polygraph examination can be used as evidential argument only if the accuracy of the technique reaches at least $90 \%$. Taking a substance-blind approach into account, one can assume that the result of polygraph examination supports the conclusion of evidential argument with high significance. It is generally known that there are various scales for the verbalisation of the numerical description of probability. The application is a question of convention. According to one of them, the level of (objective) conviction of the addressee of the argument in case of probability exceeding $90 \%$ is expressed in the sentence "I am positive (that $A$ )", and the objective strength of support for the conclusion (in our case $A$ ) is overwhelming (Anderson, Schum, Twining 2005: 230).

Obviously, such a situation is valid only in the case when the fact that is to be proved by polygraph examination is defined correctly and accurately. This concerns already the use of polygraph examination as evidential argument in a chain of reasoning as part of the mass of evidence, and usually while treating the case as a whole. This was noticed by J. Widacki (2014), who remarked that a polygraph examination usually provides indirect evidence in proving fact in issue.

In this context, there is one more important problem that needs paying attention to. Namely that the analyst's tasks include also the assessment of the structure of evidence. This concerns the determination of mutual relations between the individual items of evidence. They can be corroborative or conflicting (in other words: convergent or divergent) towards one another. Most generally speaking, items of evidence are mutually corroborative (convergent) if they support the same claim. The phenomenon is also defined as redundancy. Redundancy is cumulative, if one of the items of evidence that support a claim together provides novelty into its justification (Schum 2001: 391 and ff). For example, (to keep the case simple: without generalisations and ancillary evidence):

(a) Giving a negative answer to the relevant question concerning participation in breaking into $M$ 's house, person $X$ was deceptive (DI indicated), 
(b) Witness $S$ saw person $X$ breaking into $M$ 's house through a window. Certainly, these statements are mutually convergent, and one corroborates the other.

Yet a polygraph examination may provide more information than the above, namely:

(a) Giving a negative answer to the relevant question concerning participation in breaking into $M$ 's house, person $X$ was deceptive (DI indicated),

(a') Person $X$ knows the following details of burglary in $M$ 's house:

- $X$ knows that the burglar entered through a window

- $X$ knows that a sum of CHF 1000 was stolen from M's house

- $X$ knows that the money was in a locker behind a copy of Mona Lisa, although $X$ denies it.

(b) Witness $S$ saw person $X$ breaking into $M$ 's house through a window.

The statement (a'), obtained as a result of conducting a polygraph examination, significantly increases the support for the claim to be proved by evidence, therefore, what we deal with is a cumulative redundancy. This is worth remembering: analysts should not limit their involvement to testing the status of the general conclusion from polygraph examination, but also consider the relevant questions of the tests applied if the expert does not emphasise its significance. On the other hand, it is a well-known fact that one issue tests are more precise than multi issue tests, and the admissibility of POT tests as a proof may sometimes be questioned.

In the case of divergence within the mass of evidence, for example:

(a) Giving a negative answer to the relevant question concerning participation in breaking into M's house, person $X$ was deceptive (DI indicated),

(b) Witness $S$ saw person $X$ in a bar in Boston at the time when $M$ 's house was burgled in Kraków.

Seeking for new pieces of evidence will be decisive, but so will be a very detailed analysis of ancillary evidence in (a) and (b).

\section{Conclusions}

1. The result of a correctly conducted polygraph examination, assessed through a substance-blind approach, is a highly valuable element of evidential argumentation.

2. Pointing to accurate pieces of ancillary evidence is of key importance in analytical assessment of correctness of examination. Such validation must 
at least prove that the examination technique applied was correct, the expert was appropriately certified, and the laboratory where the examination was conducted was accredited, or equally powerful proofs analogous to the above are provided.

3. Analysis of the result of a polygraph examination should encompass the precise definition of the fact that the result is to prove.

4. Analysis of this result should cover also its position in the mass of evidence while considering the case as a whole. Special attention should be paid to the determination of convergence or divergence of the result of polygraph examination with other elements of evidence.

5. A polygraph examination may be used, quite naturally, to acquire cumulative convergence (redundancy). This circumstance deserves attention both in the analysis and in the preparation of the examination for each case.

\section{References}

T. Anderson, D. Schum, W. Twining, (2005), Analysis of Evidence, Cambridge University Press, Cambridge.

F. Horvath, (2000), Polygraph, [in:] J.A. Siegel, P.J. Saukko, G.C. Knupfer (eds.), Encyclopedia of forensic sciences, Academic Press, San Diego, Vol. 3.

A. Ibek, (2011), The result of a polygraph examination as an argument in criminal investigation, European Polygraph, Vol. 5, No. 3-4.

M. Gołaszewski, (2013), Standardy APA dotyczące badań dowodowych, [in:] M. Gołaszewski (ed.) Wspótczesne standardy badań poligraficznych, Agencja Bezpieczeństwa Wewnętrznego, Warszawa.

D. Krapohl, (2006), Validated Polygraph Techniques, Polygraph, Vol. 35, No. 3.

Meta-analytic survey of criterion accuracy of validated polygraph techniques. Report Prepared for the American Polygraph Association Board of Directors, Polygraph Special Edition, Vol. 40, No. 4.

D.C. Raskin, Ch.R. Honts, (2002), The comparison question test, [in:] M. Kleiner (ed.), Handbook of Polygraph Testing, Academic Press, San Diego.

B. Schiffer, E. Stauffer, (2009), Accreditation: organizational, [in:] A. Jamieson, A. Moenssens (eds.), Wiley encyclopedia of forensic science, Vol. 1, Wiley, Chichester. 
J.R. Spencer, (2000), Evidence and Forensic Science, [in:] F.J. Nijboer, W.J.J.M. Sprangers (eds.), Harmonisation in Forensic Expertise. An inquiry into the desirability of and opportunities for international standards, Thela Thesis, Amsterdam.

E. Stauffer, B. Schiffer, (2009), Training and Certification (in Criminalistics), [in:] A. Jamieson, A. Moenssens (eds.), Wiley encyclopedia of forensic science, Vol. 5, Wiley, Chichester.

W. Twining, (2006), Rethinking Evidence. Exploratory Essays, Cambridge University Press, New York.

D. Walton, (2008), Witness Testimony Evidence. Argumentation, Artificial Intelligence, and Law, Cambridge University Press, Cambridge.

J. Widacki, F. Horvath, (1978), An experimental investigation of the relative validity and utility of the polygraph technique and three other common methods of criminal identification, Journal of Forensic Science, No. 23 (3).

J. Widacki, (2014), Results of polygraph examination: direct or circumstantial evidence? European Polygraph, Vol. 8, No. 2. 